\section{AB0432 SURVIVAL AND PROGNOSIS IN SYSTEMIC SCLEROSIS: RESULTS FROM A SINGLE-CENTER COHORT}

M. Rojas-Giménez ${ }^{1}$, R. Ortega Castro ${ }^{1}$, C. López-Medina ${ }^{1}$, J. Calvo Gutierrez ${ }^{1}$, M. Á. Aguirre-Zamorano ${ }^{1}$, A. Escudero Contreras ${ }^{1} .{ }^{1}$ Reina Sofia University Hospital, Maimonides Institute for Research in Biomedicine of Cordoba (IMIBIC), Córdoba University (UCO), Córdoba, Spain., Cordoba, Spain

Objectives: To analyze survival, causes of death, and risk factors associated with mortality in a cohort of patients with Systemic Sclerosis (SSc) at a single center

Methods: We performed a retrospective observational study of a cohort of patients with SSc undergoing follow-up during 2012 and until August 2020. We used the Kaplan-Meier method to estimate survival from onset of symptoms and multivariate Cox regression analysis to obtain independent risk factors associated with mortality

Results: The study population included 85 patients (women, $85.8 \%$; mean age at diagnosis, $64.4 \pm 12.7$ years). A total of 19 patients $(22.6 \%$ ) died (table 1 ). Of these $11(57.9 \%)$ died of a cause related to the disease itself (interstitial lung disease [ILD], 5 (26.3\%); pulmonary hypertension, $2(10.5 \%)$; or a combination of both, $3(15.8 \%)$. The main cause of non-SSc-related death was cancer $(21.1 \%)$. Survival rates at 5,10 , and 20 years were $98 \%, 92 \%$, and $75 \%$, respectively. Survival was statistically significantly poorer for the absence of ACA, the presence of antitopoisomerase I antibodies, proximal skin thickening, pulmonary hypertension, ILD, cancer and the diffuse subtype. The multivariate analysis performed to determine which factors were independently associated with mortality confirmed that older age at diagnosis of the disease, lower FVC in spirometry at diagnosis of ILD, and proximal skin thickening were associated with greater mortality

Table 1. Clinical and immunological characteristics of patients who died and patients who lived

\begin{tabular}{|c|c|c|c|}
\hline & $\begin{array}{c}\text { Dead } \\
(n=19)\end{array}$ & $\begin{array}{c}\text { Alive } \\
(n=66)\end{array}$ & $p$-value \\
\hline Female sex, n (\%) & 17 (89.5) & $55(83.3)$ & 0.594 \\
\hline Age at diagnosis (years), mean (SD) & $56.9(13.7)$ & $50.4(13.6)$ & 0.076 \\
\hline Time since diagnosis (years), mean (SD) & $11.6(7.3)$ & $14.2(9.2)$ & 0.215 \\
\hline IcSSc, n (\%) & $6(33.3)$ & $50(75.7)$ & $<0.001$ \\
\hline dcSSc, n (\%) & $12(66.7)$ & $10(15.1)$ & $<0.001$ \\
\hline Digital ulcers, n (\%) & $9(47.4)$ & $33(50)$ & 0.748 \\
\hline Calcinosis, n (\%) & $1(5.3)$ & $16(24.2)$ & 0.061 \\
\hline Telangiectasias, n (\%) & 15 (78.9) & $56(84.8)$ & 0.184 \\
\hline ILD, n (\%) & 15 (78.9) & $32(48.5)$ & 0.021 \\
\hline $\mathrm{FEV}_{1}$ at diagnosis of ILD, mean (SD) & $78.3(19.3)$ & $78.7(17.7)$ & 0.955 \\
\hline $\mathrm{FVC}^{1}$ at diagnosis of ILD, mean (SD) & $65.2(13.1)$ & $78.1(20.7)$ & 0.043 \\
\hline DLCO at diagnosis of ILD, mean (SD) & $56.9(17.5)$ & $63.9(16.7)$ & 0.301 \\
\hline Pulmonary hypertension, n (\%) & $11(57.9)$ & $14(21.9)$ & 0.002 \\
\hline $\operatorname{sPAP}(\mathrm{mmHg})$, mean $(\mathrm{SD})$ & $49.2(24.7)$ & $30.2(8.2)$ & 0.009 \\
\hline Gastrointestinal involvement, $\mathrm{n}(\%)$ & $13(68.4)$ & $30(45.4)$ & 0.125 \\
\hline Cardiac involvement, $\mathrm{n}(\%)$ & $3(15.8)$ & $11(16.7)$ & 0.907 \\
\hline Muscle involvement, $\mathrm{n}(\%)$ & $1(5.3)$ & $2(3.03)$ & 0.851 \\
\hline Arthritis or arthralgia, $\mathrm{n}(\%)$ & $5(26.3)$ & $23(34.8)$ & 0.436 \\
\hline Renal crisis, $\mathrm{n}(\%)$ & 0 & $2(3.03)$ & $<0.001$ \\
\hline Cancer, n (\%) & $5(26.3)$ & $2(3.03)$ & 0.001 \\
\hline Positive ACA, n (\%) & $5(26.3)$ & $35(53.03)$ & 0.034 \\
\hline Positive ATA, $n(\%)$ & $10(52.6)$ & $9(13.6)$ & $<0.001$ \\
\hline
\end{tabular}

Abbreviations: ILD: diffuse interstitial lung disease, SSc: systemic sclerosis, FEV : forced expiratory volume in the first second, FVC: forced vital capacity, DLCO: diffusing capacity for carbon monoxide, SPAP: systolic pulmonary artery pressure, ACA: anticentromere antibody, ATA: antitopoisomerase I antibody.

Conclusion: Survival at 10 years was greater than $90 \%$ in the study cohort. The main causes of death were ILD, pulmonary hypertension and cancer. The main factors associated with mortality were proximal skin thickening, older age at diagnosis, and lower forced vital capacity

Disclosure of Interests: None declared

DOI: 10.1136/annrheumdis-2021-eular.1777

\begin{tabular}{|l|l}
\hline AB0433 & STUDY DESIGN FOR THE RANDOMISED \\
CONTROLLED PHASE II RESSCUE TRIAL: SAFETY \\
AND EFFICACY OF FAECAL MICROBIOTA \\
TRANSPLANTATION BY ANAEROBIC CULTIVATED \\
HUMAN INTESTINAL MICROBIOME (ACHIM) IN \\
PATIENTS WITH SYSTEMIC SCLEROSIS
\end{tabular}

H. Fretheim ${ }^{1}$, I. Barua ${ }^{1}$, V. Sarna ${ }^{2}$, M. N. Carstens ${ }^{1}$, O. Distler ${ }^{3}$, D. Khanna ${ }^{4}$, E. Volkmann ${ }^{5}$, Ø. Midtvedt ${ }^{1}$, H. Didriksen ${ }^{1}$, A. Dhainaut ${ }^{6}$, A. K. H. Halse ${ }^{7,8}$, G. Bakland ${ }^{9}$, I. C. Olsen ${ }^{10}$, M. E. Pesonen ${ }^{10}, \varnothing$. Molberg $^{1}$, A. M. Hoffmann-Vold ${ }^{1}$. ${ }^{1}$ Oslo University Hospital, Department of Rheumatology, Oslo, Norway; ${ }^{2}$ Oslo University Hospital, Department of Gastroenterology, Oslo, Norway; ${ }^{3}$ University Hospital Zurich, Department of Rheumatology, Zurich, Switzerland; ${ }^{4}$ University of Michigan, Division of Rheumatology, Ann Arbor, United States of America; ${ }^{5}$ University of California, Division of Rheumatology, Los Angeles, United States of America; ${ }^{6}$ St. Olavs hospital, Department of Rheumatology, Trondheim, Norway; ${ }^{7}$ University of Bergen, Department of Clinical Science, Bergen, Norway; ${ }^{8}$ Haukeland University Hospital, Department of Rheumatology, Bergen, Norway; ${ }^{9}$ University Hospital of Northern Norway, Department of Rheumatology, Tromsø, Norway; ${ }^{10}$ Oslo University Hospital Research Support Services, Oslo Centre for Biostatistics and Epidemiology (OCBE), Oslo, Norway

Background: Gastro-intestinal tract (GIT) symptoms is highly prevalent in patients with systemic sclerosis (SSc). The GIT-symptoms impact on the quality of life is significant, and available treatment alternatives are limited. Recently published articles show associations between gut microbiota changes and GIT-symptoms in SSc. We, therefore, performed a successful feasibility trial on faecal microbiota transplantation (FMT) in SSc patients using the single-donor bacterial culture "Anaerobic Cultivated Human Intestinal Microbiome (ACHIM)" Based on the promising results from the feasibility trial, we aim to evaluate the safety and efficacy of FMT by ACHIM in SSc patients. (NCT04300426)

Objectives: To design a clinical trial that explores the safety and efficacy of FMT in SSc patients.

Methods: The ReSScue trial is a phase II, placebo-controlled, randomised 20-week, multicentre trial. The trial comprises three parts. In the induction phase (A1) lasting from week 0 to week 12, participants are randomised 1:1 to repeat infusions of $30 \mathrm{ml} \mathrm{ACHIM} \mathrm{or} \mathrm{placebo} \mathrm{at} \mathrm{week} 0$ and 2 by gastro-duodenoscopy. In the maintenance phase (A2), all study participants will receive $30 \mathrm{ml} \mathrm{ACHIM}$ at week 12 and are followed continued blinded until week 20.

For longer-term data on intervention effects and safety, the participant will be followed for a maximum extended monitoring period of 16 weeks (part B).

The primary endpoint is change from baseline to week 12 in UCLA GIT scores on bloating or diarrhoea, depending on the worst symptom at baseline evaluated separately for each patient. Secondary endpoints are changes in UCLA GIT scores (bloating, diarrhoea and total) and safety measures.

Results: We aim to enrol 70 SSc patients based on the power calculations for the primary endpoint "change in worst symptom from baseline to week 12", with a considered drop out rate of $10 \%$. This number of patients is expected to give a power of $80 \%$ of detecting a change in mean ( $p=0.05$, two-sided) of -5.0 (or higher) if the relating standard deviation is 0.70 or lower. The patient screening started in September 2020, and we expect the study to be completed in May 2022.

Conclusion: The ReSScue-study is to our knowledge the first FMT-study in SSc. This trial will assess the safety and efficacy of FMT in SSc patients with lower GI-symptoms, possibly leading to a novel treatment approach in SSc patients.

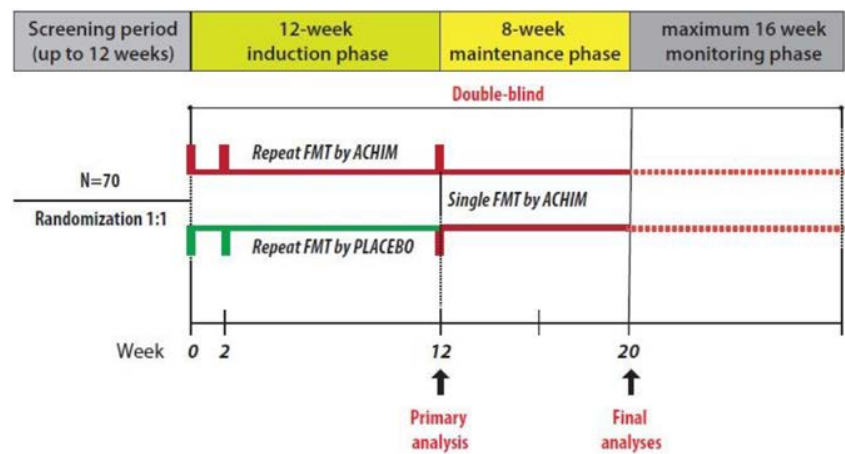

Disclosure of Interests: Håvard Fretheim Grant/research support from: Received travel bursaries from Actelion, and remuneration from Bayer., Imon Barua: None declared, Vikas Sarna: None declared, Maylen N Carstens: None declared, Oliver Distler Speakers bureau: Below, Consultant of: Below, Grant/ research support from: OD has/had consultancy relationship and/or has received research funding in the area of potential treatments for systemic sclerosis and its complications from (last three years): Abbvie, Acceleron Pharma, Amgen, AnaMar, Arxx, Baecon Discovery, Blade, Bayer, Boehringer Ingelheim, Chem omAb, Corbus, CSL Behring, Galapagos NV, Glenmark, GSK, Horizon (Cur zion), Inventiva, iQvia, Italfarmaco, iQone, Kymera, Lilly, Medac, Medscape, Mitsubishi Tanabe Pharma, MSD, Novartis, Pfizer, Roche, Sanofi, Serodapharm, Topadur, Target Bioscience and UCB. Patent issued "mir-29 for the treatment of systemic sclerosis" (US8247389, EP2331143)., Dinesh Khanna Consultant of: Abbvie, Actelion/Janssen, Acceleron Pharma, Amgen, Bayer, Boehringer Ingelheim, CSL Behring, GSK, Horizon Pharmaceuticals, Mitsubishi Tanabe Pharma, Pfizer, Roche, Sanofi, United Therapeutics. DK is chief medical officer of Eicos Sciences, Inc., Grant/research support from: Abbvie, Actelion/Janssen Acceleron Pharma, Amgen, Bayer, Boehringer Ingelheim, CSL Behring, GSK Horizon Pharmaceuticals, Mitsubishi Tanabe Pharma, Pfizer, Roche, Sanofi, 